\title{
Spatio-Temporal Patterns of Wildlife Road Mortality in Golestan National Park-North East of Iran
}

\author{
Vahed Dehghani Kazemi*, Hamidreza Jafari, Ahmadreza Yavari \\ Department of Environmental Planning, Graduate Faculty of Environment, University of Tehran, Tehran, Iran \\ Email: *Vdehghani@ut.ac.ir
}

Received 6 April 2016; accepted 10 May 2016; published 13 May 2016

Copyright (C) 2016 by authors and Scientific Research Publishing Inc. This work is licensed under the Creative Commons Attribution International License (CC BY). http://creativecommons.org/licenses/by/4.0/

\section{Abstract}

Nowadays, wildlife road mortality is acknowledged as a main source of threatening long-term survival of wildlife. This paper as the first to analysis wild life vehicle collisions in Iran, aims to reconstruct and interpret the spatio-temporal patterns of WVCs on Asiaei highway in Golestan National Park (GNP). With the collaboration of environmental protection department of GNP, we identified about 1900 WVC Records involving 34 different species of mammals, birds, reptiles and amphibians between 2004 and 2013. Mammals were involved in more than $50 \%$ of overall WVCs, among which wild boar (Sus scrofa), Golden Jackal (Canis aureus), Red Fox (Vulpes vulpes), hedgehog (Erinaceus concolor), stone marten (Martes foina) and porcupine (Hystrix indica) were involved in more than $\mathbf{9 0 \%}$ of mammals' mortalities; So, we focused on analyzing spatio-temporal pattern of vehicle collisions of these six mammal species. During the study period, these species have undergone 95\% increase in road mortalities, averagely. Detailed temporal analyses exhibited an increasing trend of road mortalities from spring to summer and then a reducing one to late winter. It was shown that a large number of collisions occurred in holiday periods when recreational trips considerably increased the traffic volume of Asiaei highway. Preliminary inspection of spatial patterns using Kernel density analysis revealed six collision hotspots, mostly located in the road bends with densely forested land cover on both sides; the promenades along the road seemed to play a significant role too. Scale dependency analyses of collision patterns, demonstrated clustering pattern at micro scales less than $10 \mathrm{~km}$, randomness at meso scales $10-20 \mathrm{~km}$ and both regularity and clustering at macro scales more than $20 \mathrm{~km}$. This paper suggests that road mortality of common species in GNP is a momentous issue, which needs to be considered by relevant governmental and public organizations. We also emphasize that the analyses of spatial and temporal patterns of WVCs are fundamentals to plan for mitigate wildlife road mortality.

${ }^{*}$ Corresponding author. 


\section{Keywords}

\section{Golestan National Park, Wildlife Vehicle Collision (WVC), Spatio-Temporal Pattern, K-Function}

\section{Introduction}

To meet the demands of increasing human population and economic development, in past decades, the road networks were expanded and volume of traffic has rapidly increase [1]. Roads can affect wildlife in numerous different ways, both direct and indirectly. Habitat loss, degradation and fragmentation [2] [3], as well as animal mortality [4] [5] are acknowledged as direct and reduction of permeability [6], barrier effects [7] and loss of connectivity [8] [9] are indirect effects, which collectively reduce long-term survival and population viability [10]. Nowadays, besides of commercial exploitation, pollutions and introduced species, non-natural sources of mortality of wildlife, road mortality has become a serious source of wildlife mortality worldwide [11]. As roads are built and expanded in rural areas, the rate of wildlife-vehicle collisions increases dramatically [12]. On a 50 kilometers coastal road of Colombia, eighteen months Survey indicated 216 vertebrate deaths [13]. By threatening traffic safety and causing traumas and even in some cases death of car drivers or passengers, WVCs not only have ecological but also economic and social consequences [14]. In the United States, the total number of annual deer vehicle collision was estimated at more than 1 million in the early 1990s [15] causing 155 - 211 human fatalities, 13,713 - 29,000 human injuries and more than 1 billion US \$ in property damage a year [15] [16]. In 2000, Canada experienced more than 30,000 collisions with animals resulting in 23 human fatalities, 1887 human injuries and more than 60 million US \$ in property damage [17]. Similar figures are available from Europe, where in France this cost has been evaluated to 200 million Euros for the year 2003, much more than the cost of damage to agriculture by wildlife for the same period [18]. The conflict between the transportation infrastructure and the natural environment will increase, due to the inevitable need for transportation development and subsequent growth in traffic volume. The remaining challenge is that, how current and future transportation networks can be modified towards establishing a sustainable transport system. To prevent WVCs, road and wildlife managers need to know about the critical times and spaces that particular species are susceptible to high road-kill rates. Having accurate information on both hot times and locations of WVCs, more effective mitigation measures, established at the right time and the right place, are expected. It is acknowledged that WVCs have temporal and spatial patterning [19]-[22]. While temporal variations in traffic kills can be linked to animal activity and behavior (which in turn are determined by biological characteristics e.g. the daily rhythm of foraging and resting, periodical migrations, mating and breeding habits and dispersal of juveniles) [23]-[25], key elements that affect the spatial patterns are population density, landscape structure and habitat distribution [26]. Location and timing of accidents can also be influenced by traffic and road related factors [22] [27] [28], as well as temporary variations of environmental factors e.g. temperature, rainfall or snow cover [29].

In recent decades, both population and economic growth in Iran, have led to development of transportation infrastructures. Construction of new roadways and renovation of existing ones have resulted in fundamental changes in natural landscapes all over the country. The Asiaei highway, a critical road in northeast of Iran, as a perfect example of renovation cases, has led to Impressive adverse effects on natural landscape of Golestan National Park (GNP); among which, vehicle collision of valuable wildlife is a critical issue [30], must be investigated more precisely. Despite of frequently occurring road related mortality of wildlife in protected areas of the country, no study has ever attempted to summarize and interpret their patterns. Reconstructing the spatial patterns and timing of wildlife road mortality in Golestan National Park is required for diagnosing conflicting areas and times, making effective decisions to mitigate road mortality effects on scarce low density wildlife of this biosphere reserve as well as improving passenger's safety [11]. Nonetheless, there is no existing research that has investigated the spatio-temporal pattern of WVCs in Iran. Thus, in this study, we aimed to examine the spatial and temporal patterns of WVCs on the Asiaei highway, a pioneering research in Iran, addressing hot places and times of WVCs, helping sustainable transportation infrastructures utilization and development. In this context, we aim to: 1) quantify the numbers and exact locations of road mortalities of each species, 2) compare the numbers of fatalities among the species, 3) address the monthly, seasonal and annual distribution of mortalities, 4) present wildlife fatality hot spots and, 5) examine scale dependency of collision patterns. 


\section{Material and Method}

\subsection{Study Area}

Our study area is the Golestan National Park (GNP), the north east part of Iran, ranging between $37^{\circ} 824^{\prime} \mathrm{N}$ and $55^{\circ} 58^{\prime} \mathrm{E} 37.403^{\circ} \mathrm{N}$ and $55.976^{\circ} \mathrm{E}$ [31]. The park has an area of 87402 ha Located in Golestan, North Khorasan and Semnan Provinces (Figure 1). Having been protected since 1957, it became the first national park of Iran in 1967 prior to its recognition as a biosphere reserve in 1976. Nowadays, GNP is the most important protected area of Iran with great habitats for many wildlife species of which some are included in IUCN red list of threatened species [32] [33]. The average annual precipitation in GNP is $400 \mathrm{~mm}$ and the annual average temperature is $11.98^{\circ} \mathrm{C}$. Gradually reducing toward the east, the elevation ranges from 450 to $2,400 \mathrm{~m}$ above sea level. The mean annual precipitation is 150 in east and $700 \mathrm{~mm}$ in the west part [31] [32] [34]. The vegetation can be divided into two zones: the Hyrcanian forest in the west with a high humidity and the Iran-Turanian vegetation in the east of the park where it is dry [35].

A two lane highway, the Asiaei is of national importance in that it provides the main access to Mashhad, a metropolis of tourism importance. Thus, in weekends and holidays, traffic volume of the Asiaei highway is two to three times more than working days (average 3920 and 13,188 vehicles per day in working days and holidays, respectively). Most of the traffic comprises passenger vehicles (84\%), the rest being truck and lorries [30]. Speed limit on the highway is 85 in night and $95 \mathrm{~km} / \mathrm{h}$ in day. On $35 \mathrm{~km}$ of its length, the highway runs through the park and divides it into northern and southern parts; then, it goes along to the end of southern boundary of the park at Gharehbil village [36]. The history of the road dates back to the late 1980s, when it was a dirt road utilized as local access road to different parts of the park. Later, the paved and widened road became a national highway with a great volume of daily traffic. Annually, numerous wildlife vehicle collisions are reported on this road, resulting in valuable rare species death.

\subsection{Wildlife Vehicle Accident Data}

There are many sources of WVCs data, insurance companies [37], transportation management agencies at local and national scale [38] [39], police road accident databases [40] [41] and so on, each focusing on specific subjects. In our case, the environmental protection department of GNP is directly responsible for managing the park issues. On this way, WVCs are recorded through daily patrolling along the highway. We used the WVC database of 10 years (2004 to 2013), involving about 1900 Records for mammal, birds, reptiles and amphibian species. Data collected for each accident were included species involved, date and vernacular name of location. The location of collisions were also recorded by a GPS set with an accuracy of $200 \mathrm{~m}$ and transferred the data to GIS software.

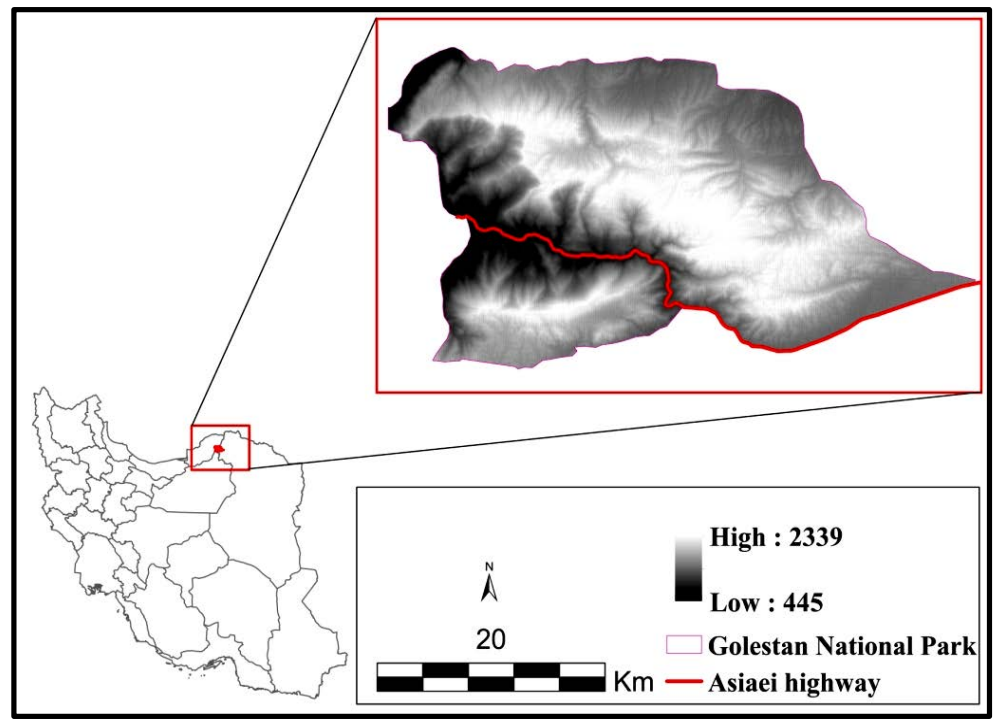

Figure 1. Golestan national park and the Asiaei highway. 


\subsection{Temporal and Spatial Pattern Analysis}

Annual, seasonal and monthly patterns of collisions were the subjects of temporal pattern analyses. On this way, temporal variations in frequencies of roadkills were examined applying excel diagrams; We also used Chisquare goodness of fit test to Investigate if there were significant variations in relative frequencies of roadkills [12]. To analysis spatial pattern of WVCs, firstly, using kernel density estimation [42], hotspots of WVC for all roadkills were identified and spatial point distributions inspected visually. Secondly, WVCs spatial structure at various spatial scales was examined using the Global auto K function [43]. SANET ${ }^{\circledR}$ 4.1. Beta [44] under ArcGIS 10.2 was used for spatial pattern analyses.

\subsection{Kernel Density Analysis}

Kernel Density Analysis is a traffic accident clustering method not only reveals the clustering or dispersion tendency of traffic accidents but also the hotspots location of accidents [18]. To identify hotspots, Kernel density calculates the number of collisions per kilometer of roads. The bandwidth of the kernel exhibits a strong influence on the estimation results. The bandwidth determines the search radius in which roadkills will contribute to the hotspot identification [18]. We used a search radius of $500 \mathrm{~m}$ to investigate collision clusters, a reasonable distance between mitigation measures in hot spots (if necessary) [45]. The estimator of network kernel density is:

$$
\lambda(s)=\sum_{i=1}^{n} a_{i} \frac{1}{t} k\left(\frac{d_{i s}}{r}\right)
$$

where $\lambda(s)$ is the density at location $s ; t$ is the band width; $d_{i s}$ is the distance from the estimation to the observation point $i$; $k$ is the function of ratio between $d_{i s}$ and $t$ to measure the distance decay effect and $a_{i}$ is the number of points at $s$.

\subsection{Ripley K Function}

Wildlife roadkill patterns, regarding to species intrinsic and extrinsic characteristics, occur at different spatial scales [22] [45]. To examine scale dependency of WVC patterns, The K-function method was used. As an advantage, K-function analysis does not include just the nearest neighbor but it uses all point-point distances, to show spatial clustering [42]. However, to calculate the Euclidean distance between points, it assumes that the environment is homogenous. So, in case of irregular road networks it can result in over detection of clustering patterns [43] [46]-[48]. To conduct K-function analysis of point data on networks more precisely, Okabe and Yamada (2001) developed a new method of K function, so called network K function (instead of Planer K function) [43] [49]. Ripley K function is Originally used for two dimensional applications, In our case, because of small width of road compared with its length, distribution of roadkill points assumed one dimensional and Global auto K function provided by the SANET was used [40] [43] [49]. Investigating WVCs in GNP, network Kfunction calculated as Equation (1):

$$
\hat{K}(t)_{\text {network }}=\frac{R L_{T}}{n(n-1)} \sum_{i=1}^{n}\left(P \in R L_{p}(t)\right)
$$

where $n$ is sample size, $R L_{p}$ is a section of entire road network $\left(R L_{T}\right)$, and $P$ includes the number of WVC points on $R L_{T}$ within a distancet of point $i$ [49]. Using the Global auto K function In SANET, for each $500 \mathrm{~m}(t=500$ m) along $R L_{T}$, we computed an observed and an expected spatial distribution of real and random WVC points respectively [49]. To investigate the significance of departure of the network $\hat{K}(t)$ from CSR, the deviation of the observed number from expected number of points were plotted againstt. To calculate expected values and constructing confidence envelope, Monte-Carlo simulations of random points distributed along the road network $\left(R L_{T}\right)$ was applied (100 simulations). If plot of $\hat{K}(t)$ lie outside the upper and lower confidence intervals, then points of $\mathrm{P}$ are tending to clustering and regularity, respectively. Conversely, $\hat{K}(t)$ values lied within the confidence envelope represent random distribution of points $\mathrm{P}$ [40] [43] [45].

\section{Results}

In total about 1900 WVCs of 34 different species of mammals (21 species), birds (8 species), reptiles and am- 
phibians (5 species) were identified in GNP. Mammals were involved in more than 50\% of total WVCs among which wild boar (Sus scrofa), Golden Jackal (Canis aureus), Red Fox (Vulpes vulpes), hedgehog (Erinaceus concolor), stone marten (Martes foina) and porcupine (Hystrix indica) take the largest partmore than $90 \%$ of mammals (Table 1). So, we focused on analyzing spatio-temporal pattern of vehicle collisions of these six mammal species.

\subsection{Temporal Distribution}

Mammals' road mortality increased by $95 \%$ during the study period. Specifically, roadkill increased by $93 \%$ for wild boar, $52 \%$ for golden jackal, $242 \%$ for roe deer, $143 \%$ for red fox, $150 \%$ for porcupine, $600 \%$ for stone marten, and 300\% for hedgehog (Figure 2). The decreasing trend since 2009 to 2010 is likely due to destruction of the road by torrent and subsequently decline of traffic volume. To examine temporal pattern of road mortalities in GNP, we adjusted season and month time scales to the Iranian calendar where spring, summer, autumn and winter coincide with April-June, July-September, October-December and January-Jun, respectively. Chisquare goodness of fit test showed that accidents of all six species investigated here are not uniformly distributed seasonally. hedgehog $\left(\chi^{2}=52.7, \mathrm{df}=3, \mathrm{p}<0.05\right)$, stone marten $\left(\chi^{2}=22.7, \mathrm{df}=3, \mathrm{p}<0.05\right)$, Porcupine $\left(\chi^{2}=\right.$ 15.9, $\mathrm{df}=3, \mathrm{p}<0.05)$, red fox $\left(\chi^{2}=52.5, \mathrm{df}=3, \mathrm{p}<0.05\right)$, Golden Jackal $\left(\chi^{2}=29.3\right.$, $\left.\mathrm{df}=3, \mathrm{p}<0.05\right)$ and Wild boar $\left(\chi^{2}=113.7, \mathrm{df}=3, \mathrm{p}<0.05\right)$. In general, casualty frequencies with most of species increases in spring and summer; after that, takes a decreasing trend to the winter (Figure 3).

All species investigated showed not uniform monthly distribution of accidents (Figure 4). Casualties with hedgehog $\left(\chi^{2}=52.1, \mathrm{df}=11, \mathrm{p}<0.05\right)$ increase in April, June and September. For stone marten $\left(\chi^{2}=30.4, \mathrm{df}=\right.$ $11, \mathrm{p}<0.05)$ accidents peak also in September. In comparison to others, Porcupine $\left(\chi^{2}=20.1, \mathrm{df}=11, \mathrm{p}<0.05\right)$ and Jackal $\left(\chi^{2}=46.2, \mathrm{df}=11, \mathrm{p}<0.05\right)$ accidents are distributed more evenly, with a considerable decrease of causalities from January to March. Red fox $\left(\chi^{2}=55\right.$, df $\left.=11, \mathrm{p}<0.05\right)$ accidents show peaks in July and September and wild boar $\left(\chi^{2}=113.2, \mathrm{df}=11, \mathrm{p}<0.05\right)$ road mortalities, present high frequency from April to September and then decrease in next six months.

Table 1. Roadkilled mammals in GNP 2004-213

\begin{tabular}{|c|c|c|c|c|}
\hline Species & Scientific Name & IUCN Red List Category ${ }^{*}$ & Roadkill Number & Percentage \% \\
\hline European Badger & Meles meles & $\mathrm{LC}$ & 2 & 0.16 \\
\hline Tolai Hare & Lepus tolai & LC & 2 & 0.16 \\
\hline Bat & Rhinolophus ferrumequinum & LC & 1 & 0.08 \\
\hline Gerbil & Rhombomys opimus & LC & 3 & 0.23 \\
\hline Roe Deer & Capreolus capreolus & LC & 4 & 0.31 \\
\hline Wolf & Canis lupus & LC & 5 & 0.39 \\
\hline Red Deer & Cervus elaphus & $\mathrm{LC}$ & 5 & 0.39 \\
\hline Pine Marten & Martes martes & LC & 7 & 0.55 \\
\hline Least Weasel & Mustela nivalis & LC & 8 & 0.63 \\
\hline Leopard & Panthera pardus saxicolor & $\mathrm{NE}$ & 12 & 0.94 \\
\hline Gazelle & Gazella subgutturosa & VU & 10 & 0.78 \\
\hline Bear & Ursus arctos & $\mathrm{LC}$ & 13 & 1.02 \\
\hline Wild Cat & Felis silvestris & LC & 21 & 1.64 \\
\hline Jungle Cat & Felis chaus & $\mathrm{LC}$ & 27 & 2.11 \\
\hline Hedgehog & Erinaceus concolor & $\mathrm{LC}$ & 52 & 4.06 \\
\hline Stone Marten & Martes foina & LC & 63 & 4.92 \\
\hline Porcupine & Hystrix indica & LC & 77 & 6.02 \\
\hline Red Fox & Vulpes vulpes & LC & 106 & 8.28 \\
\hline Golden Jackal & Canis aureus & LC & 257 & 20.08 \\
\hline Wild Boar & Sus scrofa & LC & 605 & 47.27 \\
\hline
\end{tabular}

${ }^{*}$ LC: Least Concern, VU: Vulnerable, NE: Not Evaluated. 


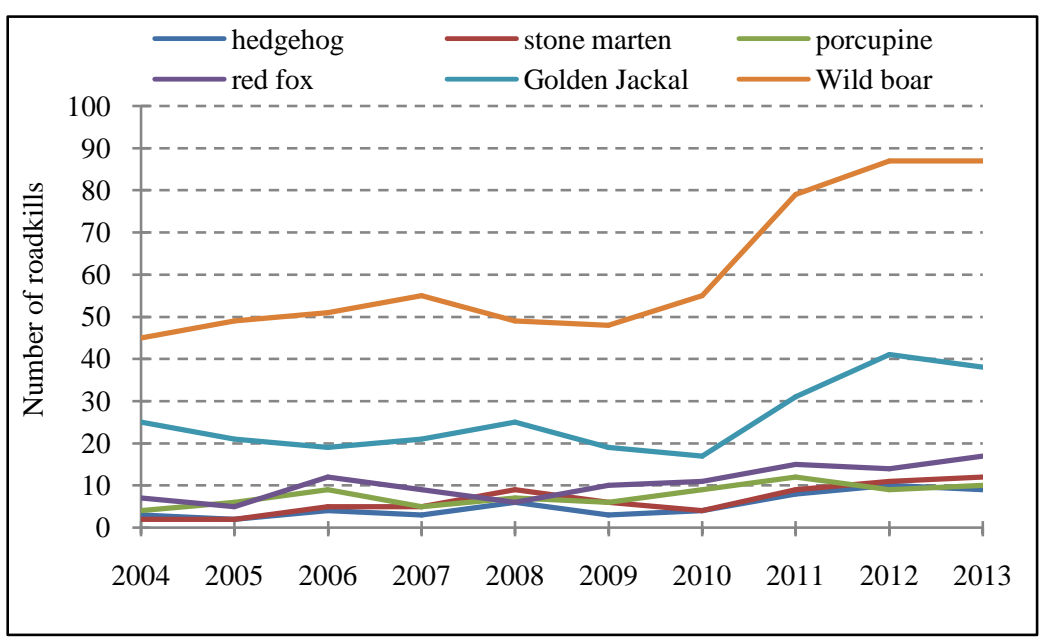

Figure 2. Annual variation of the number of accidents involving wild boar, golden jackal, red fox, porcupine, hedgehog and stone.

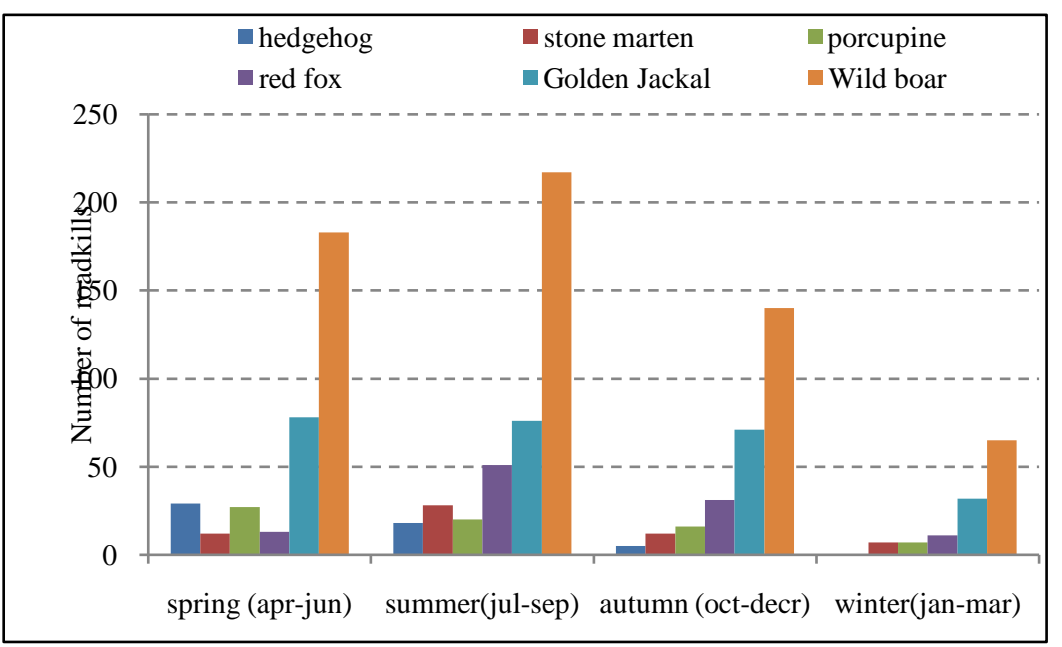

Figure 3. Seasonal distribution of casualties for investigated species.

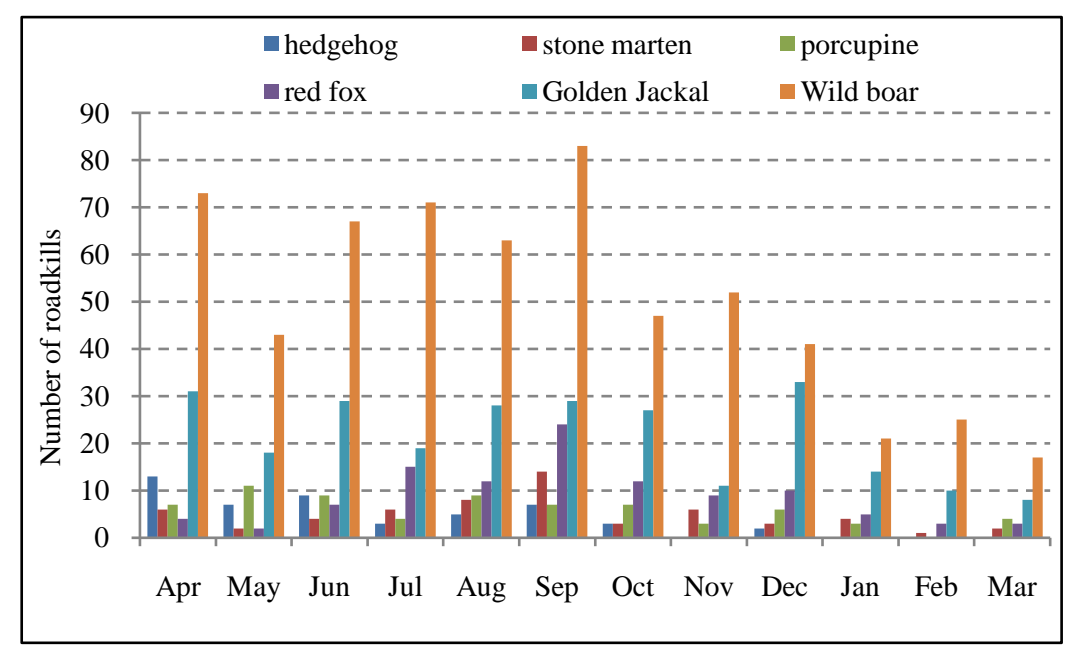

Figure 4. Monthly distribution of casualties for investigated species. 


\subsection{Spatial Pattern}

Kernel estimations of spatial point patterns density analysis, considering all species along the whole length of highway and study period, revealed heterogeneous distribution of WVCs (Figure 5). High risk areas were concentrated at $27 \mathrm{~km}$ of the western part of the highway (red rectangle in Figure 5) showing six strong clusters of road kills. Thus, subsequent spatial analyses were conducted on this section of the highway.

Univariate spatial pattern analysis using the network K-function confirmed Kernel analysis results, showing deviations from CSR at various spatial scales. Plots of $\hat{K}(t)$ versus $t$ showed deviation from CSR as well as randomness at different spatial scales. Except for boar that showed clustering pattern at all scales, others showed some degrees of clustering, randomness and regularity at different scales. Red fox road mortalities at scales 0 - 7, 7 - 23 and more than $23 \mathrm{~km}$ show clustering, randomness and regularity patterns, respectively. Stone marten, porcupine and hedgehog exhibited similar pattern, clustering at extremes and randomness at middle ranges and finally, multiple fluctuation of plot of $\hat{K}(t)$ was recorded for jackal. Figure 6 presents network K function plots of six selected mammal species.

\section{Discussion}

For the studied period, about 1900 WVCs of 34 different species of mammals, birds, reptiles and amphibians were recorded in GNP. Mammals were included in more than $50 \%$ of wildlife road mortalities and birds, reptiles and amphibians were ranked as next prevailing road killed wildlife, respectively. We didn't review the causal factors of low frequencies of accidents with birds, reptiles and amphibians in deep, however we might suspect underestimation because of removal of carcasses by scavengers. Mammals of small to medium size are the most roadkilled in GNP, so that, wild boar, jackal, red fox, hedgehog, stone marten and porcupine are involved in more than $90 \%$ of collisions of mammals. Overall road mortality numbers showed an increasing trend for these six species. The most increase in the rate of road mortality was occurred for stone marten during the study period; hedgehog, roe deer, porcupine, red fox, wild boar and golden jackal were ranked as next. Road kills rate seems to increase with Traffic intensity, road tortuosity, animal activity and population density. Wildlife road mortality is a problem with at least four main components: animal related, biological and behavioral factors (e.g. density, behavior, foraging, mating), habitat related factors (e.g. habitat patches distribution, resources availability), weather conditions (in turn, affects visibility or animal behavior) and anthropogenic causes (e.g. land use, traffic density, and driver related conditions) [38].

\subsection{Temporal Pattern}

Temporal analysis of the road mortalities of six selected species demonstrated non-uniform pattern for multiple

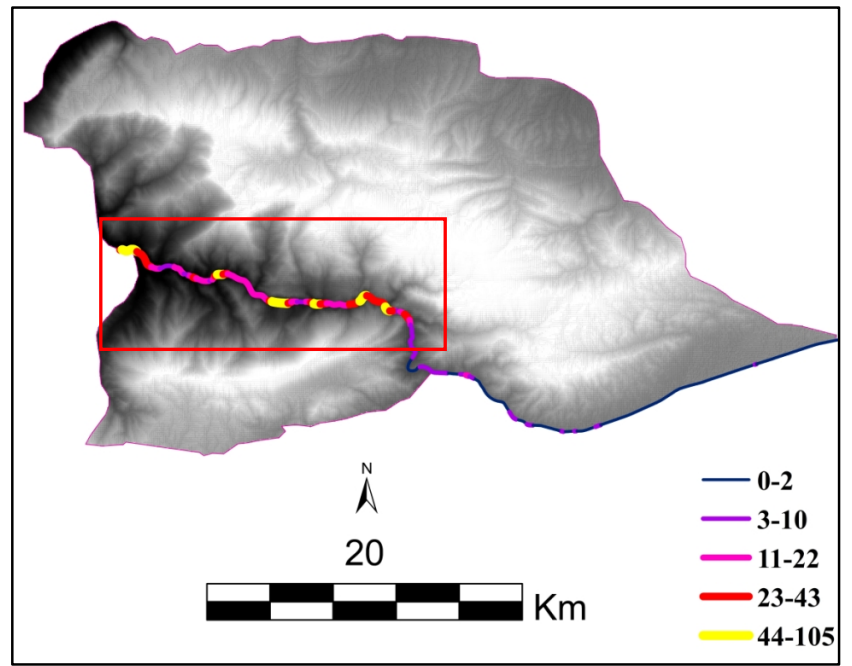

Figure 5. Kernel density estimation (WVCs per km) applying bandwidth of $500 \mathrm{~m}$. Classification method was natural breaks. 
V. D. Kazemi et al.
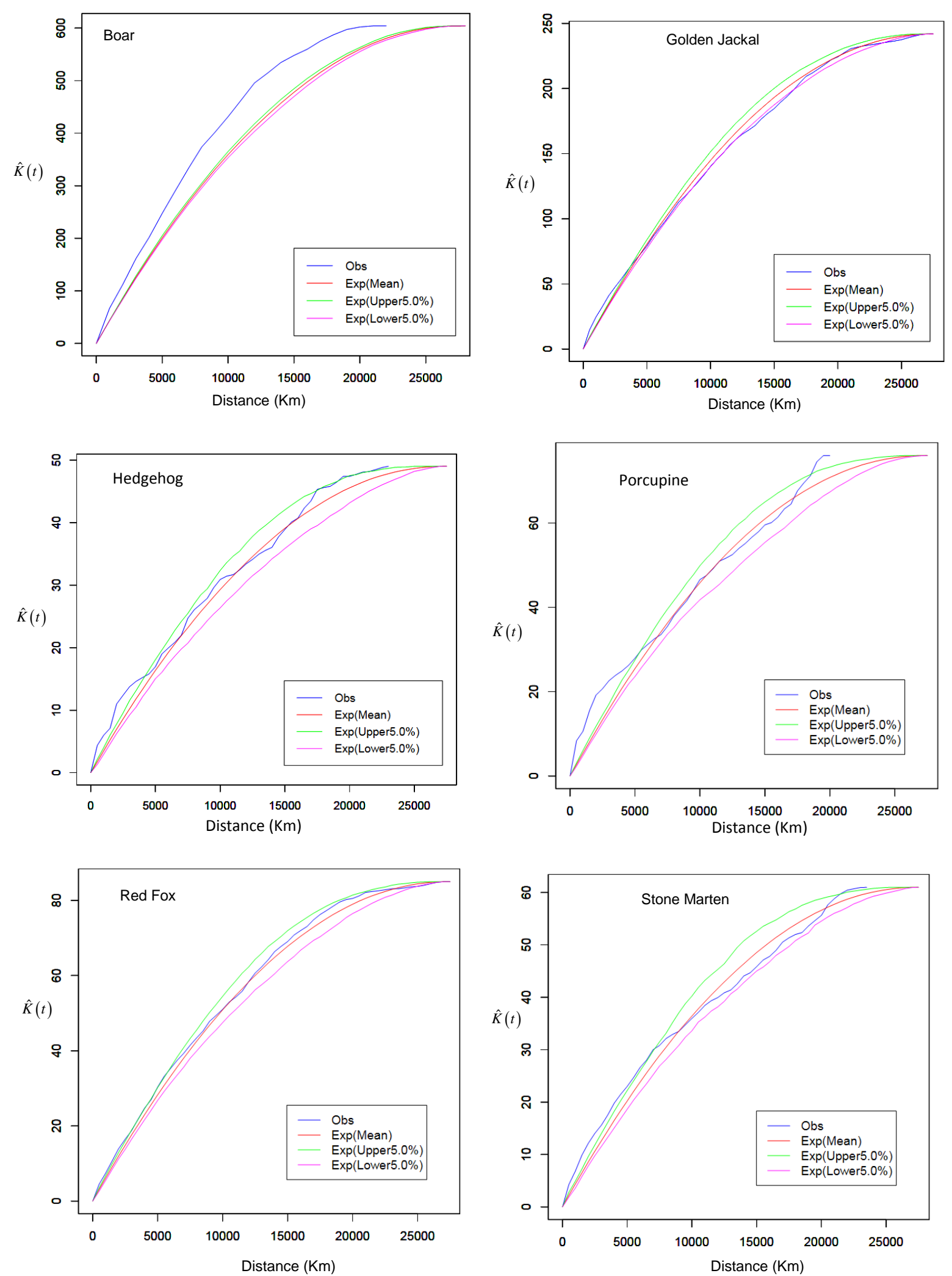

Figure 6. Univariate spatial pattern analysis using network K-function for distribution of six selected mammals roadkills in GNP, showing the observed statistic $\hat{K}(t)$ plotted against $t$ and 95\% confidence envelope for CSR. 
timescales. Except for 2009 to 2010, an annually increasing trend can be seen for the study period. Decline of traffic volume because of reconstruction of destructed road by torrent, seems to be the explanation. Seasonal and monthly peaks of road mortalities of six species investigated in spring and summer coincides with holiday times in Iran (especially April and September) which high rates of recreational trips increase the traffic volume of the Asiaei highway in these times, significantly. There are promenades along the Asiaei highway, densely populated in holidays. Remaining food of tourists attracts generalist species (red fox, jackal and boar) increasing road crossing, intensifying collision frequencies. As illustrated in Figure 5, Most of collisions occur on a section about $27 \mathrm{~km}$ of road, surrounded by dense deciduous forest which limits both drivers and wildlife field of view in these seasons. Increase in WVC In spring and summer is likely to denote the importance of land cover too. Lower recreational trip and subsequent reduction in traffic volume, expansion of field of view and reduction of wildlife activity in autumn and winter explain low WVCs in these seasons. Availability of permanent water along the western part of the highway undoubtedly accounts for the high rates of roadkills during the late dry season [50].

\subsection{Spatial Distribution}

For all road killed species, spatial analyses showed that the distribution of accidents along the Asiaei highway was not random. Although WVCs occur all over the Asiaei highway, we indeed observed highly clustering pattern along $27 \mathrm{~km}$ of western part of highway, showing six hotspots based on the result of the kernel density estimation considering all species along the whole length of highway. So we concentrated on analyzing spatial structure of accidents at various scales by means of the network $\mathrm{K}$ function on this smaller length of road. Univariate spatial pattern analyses of road kills for selected mammals confirmed deviations from CSR at various spatial scales. Except for boar, showing clustering at all spatial scales, the general patterns are clustering at micro scales less than $10 \mathrm{~km}$, randomness at meso scales from 10 to $20 \mathrm{~km}$ (except for jackal) and randomness, clustering and regularity at macro scales more than $20 \mathrm{~km}$, simultaneously. Clustering pattern of boar road mortalities at all scale ranges can be explained regarding to dramatically high collision numbers of boar all over the length of the western Asiaei highway. for red fox, jackal, stone marten, porcupine and hedgehog, Clustering patterns at micro scales may be partly due to densely killed individuals on road lengths adjacent to promenades, or because of environmental or road related factors, need to be investigated deeply. The randomness at meso scale ranges is perhaps the representation of homogenous distribution of collisions at road length except for sections bearing promenade. In general, spatial structures of WVCs can be interpreted regarding to two main general and species specific causes. Road characteristics, land cover type and availability of habitat, food and water resources are general causes; ecology, behavior and population density are species specific ones.

The western part of the Asiaei highway has characteristics may explain the clustering pattern of WVCs. more frequent tortuous sections in western part of highway, partly explains the agglomeration of collisions. According to $\mathrm{KDE}$, while there is no hot spot in eastern part of highway (31 km), six hot spots are located in western part, among which three are in sharp road bends. In addition, the speed limits of 85 and $95 \mathrm{~km} / \mathrm{h}$ for night and day respectively, are relatively high and seem not to be effective in reducing WVCs. Dense forest land cover on both sides, close to the road edges, limit the field of view of drivers and wildlife increasing collision risk [51] [52]. Certainly, habitat condition around the road affects composition and abundance of wildlife. The land cover around the western part is mainly composed of forest and ecotone of forest and meadow, to less extent. Affluence of nutrient, complexity of food chains and habitat diversity, providing high quality habitats, result in high degrees of species diversity and population density. In competitive conditions, wildlife movement increases which in turn results in increasing of road crossing and collision rate.

As stated previously, most of the mammals that die in road accidents in the Asiaei highway have willingness to road [30]. In ecological terms, road verges have considerable potential to provide ecological resources for wildlife [53]. Food scraps and other wastes along the Asiaei highway, especially in promenades, attract jackal, fox and boar. Dangerous path to these foods and feeding around road increases the collision likelihood for these three species. Indeed, in the case of generalist species like boar, fox and jackal, relatively high population density, Low dependency to high quality habitat conditions, there upon high mobility potential, and tendency to location of human presence [54] [55] seem however to reflect the root causes of car-accidents. For stone marten, porcupine and hedgehog, small body size, low mobility potential, and dark coloring pattern of body, which in turn, adversely affect visibility as well as response time of drivers, contribute to their high collision numbers. 


\section{Conclusions}

Our research is the first to begin to investigate the species involved in vehicle collisions and the temporal and spatial patterns of these accidents in Iran. Although considerable uncertainty exists, we believe our research provides an important basis to begin analyzing wildlife road mortality impacts on persistence of wildlife populations. Many species of birds, reptiles, amphibians and mammals are involved in collisions among which mammals are involved in about $50 \%$ of fatalities. In the case of mammals, wild boar, jackal, red fox, porcupine, stone marten and hedgehog are involved in more than $90 \%$ of accidents. The results endorsed the role of intrinsic wildlife characteristics as well as extrinsic ones in explaining temporal patterns of WVC occurrence. Multi-scale spatial analysis of WVCs in GNP demonstrated the clustering pattern of fatalities especially in fine scales. Increase in traffic volume, due to high recreational trips frequency in holidays, seems to affect both spatial and temporal pattern of WVCs. Maintaining viability of Common species populations, as facilitator of ecosystem processes [56] [57], is a vital component of biodiversity conservation efforts [58]. Concentration of conservation efforts already on threatened species and little attention to road mortality of common species, which in most cases constitute the majority of road-kills, remains them largely unexplored [52]. Taking both spatial and temporal components into account, the results highlight that: 1) high collision rates of common species in GNP may result in substantial decline of common species population and deficiency in their functional role and 2) there are spatial and temporal scales critical to conserve wildlife from fatality due to collision with vehicles.

The next step of our research will be dedicated to development of predictive models to identify WVC hotspots incorporating road and landscape variables and to propose mitigation measures that could enhance road permeability, functional habitat connectivity, and traffic safety. However, this is the first research on WVC in Iran. We hope it will be a start point to convincing governments, road planners and constructors so that more sustainable road transportation system could be achieved in near future.

\section{Acknowledgements}

We appreciate people who have during this 10 years period been involved in recording WVCs in GNP especially my dear friend J. Selyari. I (V. D. Kazemi) also acknowledge the constant encouragement from my Family Kimia \& Amirali.

\section{References}

[1] Kusta, T., Hola, M. and Keken, Z. (2014) Deer on the Railway Line: Spatiotemporal Trends in Mortality Patterns of Roe Deer. Turkish Journal of Zoology, 38, 479-485. http://dx.doi.org/10.3906/zoo-1308-18

[2] Ewers, R.M., Kliskey, A.D., Walker, S., Rutledge, D., Harding, J.S., and Didham, R.K. (2006) Past and Future Trajectories of Forest Loss in New Zealand. Biological Conservation, 133, 312-325. “ http://dx.doi.org/10.1016/j.biocon.2006.06.018

[3] Mata, C.I.H., Herranz, J., Suarez, F. and Malo, J.E. (2005) Complementary Use by Vertebrates of Crossing Structures along a Fenced Spanish Motorway. Biological Conservation, 124, 397-405. http://dx.doi.org/10.1016/j.biocon.2005.01.044

[4] Haines, AM., Tewes, ME., Laack, L.L., Horne, J.S. and Young, J.H. (2006) A Habitat-Based Population Viability Analysis for Ocelots (Leopardus pardalis) in the United States. Biological Conservation, 132, 424-436. http://dx.doi.org/10.1016/j.biocon.2006.04.035

[5] Roger, E., Laffan, S.W. and Ramp, D. (2007) Habitat Selection by the Common Wombat (Vombatus ursinus) in Disturbed Environments: Implications for the Conservation of a Common Species. Biological Conservation, 137, 437-449. http://dx.doi.org/10.1016/j.biocon.2007.03.001

[6] Bissonette, J.A. and Adair, W. (2007) Restoring Habitat Permeability to Roaded Landscapes with Isometrically-Scaled Wildlife Crossings. Biological Conservation, 141, 482-488. http://dx.doi.org/10.1016/j.biocon.2007.10.019

[7] Bhattacharya, M., Primack, R.B. and Gerwein, J. (2003) Are Roads and Railroads Barriers to Bumblebee Movement in a Temperate Suburban Conservation Area? Biological Conservation, 109, 37-45. http://dx.doi.org/10.1016/S0006-3207(02)00130-1

[8] Bissonette, J.A. and Storch, I. (2003) Landscape Theory and Resource Management: Linking Theory to Management. Island Press, Washington DC.

[9] Forman, R.T.T., Sperling, D., Bissonette, J.A., Clevenger, A.P., Cutshall, C.D., Dale, V.D., Fahrig, L., France, R., Goldman, C.R., Heanue, K., Jones, J.A., Swanson, F.J., Turrentine, T. and Winter, T.C. (2003) Road Ecology: Science 
and Solutions. Island Press, Washington DC.

[10] Trombulak, S.C. and Frissell, C.A. (2000) Review of Ecological Effects of Roads on Terrestrial and Aquatic Communities. Conservation Biology, 14, 18-30. http://dx.doi.org/10.1046/j.1523-1739.2000.99084.x

[11] Rodriguez, A. and Delibes, M. (2004) Patterns and Causes of Non-Natural Mortality in the Iberian Lynx during a 40Year Period of Range Contraction. Biological Conservation, 118, 151-161. http://dx.doi.org/10.1016/j.biocon.2003.07.018

[12] Griloa, C., Bissonette, J.A. and Santos-Reis, M. (2009) Spatial-Temporal Patterns in Mediterranean Carnivore Road Casualties: Consequences for Mitigation. Biological Conservation, 142, 301-313. http://dx.doi.org/10.1016/j.biocon.2008.10.026

[13] Hels, T. and Buchwald, E. (2001) The Effect of Road Kills on Amphibian Populations. Biological Conservation, 99, 331-340. http://dx.doi.org/10.1016/S0006-3207(00)00215-9

[14] Olson, D., Bissonette, A., Cramer, P., Bunnell, K., Coster, D., and Jackson, P. (2015) How Does Variation in Winter Weather Affect Deer-Vehicle Collision Rates? Wildlife Biology, 21, 80-87. http://dx.doi.org/10.2981/wlb.00043

[15] Conover, M.R., Pitt, W.C., Kessler, T.J., Dubow, K.K. and Sanborn, W.A. (1995) Review of Human Injuries, Illnesses, and Economic Losses Caused by Wildlife in the United States. Wildlife Society Bulletin, 95, 407-414.

[16] Williams, A.F. and Wells, J.K. (2005) Characteristics of Vehicle-Animal Crashes in Which Vehicle Occupants Are Killed. Traffic Injury Prevention, 6, 56-59.

[17] Tardif \& Associates Inc. (2003) Collisions Involving Motor Vehicles and Large Animals in Canada. Final Report to Transport Canada Road Safety Directorate, Ontario, 44 p.

[18] Bil, M., Andrá, R. and Janoska, Z. (2013) Identification of Hazardous Road Locations of Traffic Accidents by Means of kenrnel density Estimation and Cluster Significance Evaluation. Accident Analysis and Prevention, 265-273, 265273. http://dx.doi.org/10.1016/j.aap.2013.03.003

[19] Philcox, C.K., Grogan, A.L. and MacDonald, D.W. (1999) Patterns of Otter Lutra Lutra Road Mortality in Britain. Journal of Applied Ecology, 36, 748-762. http://dx.doi.org/10.1046/j.1365-2664.1999.00441.x

[20] Guter, A., Dolev, A., Saltz, D. and Kronfeld-Schor, N. (2005) Temporal and Spatial Influences on Road Mortality in Otters Conservation Implications. Israel Journal of Zoology, 51, 199-207. http://dx.doi.org/10.1560/3TF7-7B74-QWKC-6WV1

[21] Malo, J.E., Suarez, F. and Alberto, D. (2004) Can We Mitigate Animal Vehicle Accidents Using Predictive Models? Journal of Applied Ecology, 41, 701-710. http://dx.doi.org/10.1111/j.0021-8901.2004.00929.x

[22] Clevenger, A.P., Chruszcz, B. and Gunson, K.E. (2003) Spatial Patterns and Factors Influencing Small Vertebrate Fauna Vehicle-Kill Aggregations. Biological Conservation, 109, 15-26. http://dx.doi.org/10.1016/S0006-3207(02)00127-1

[23] Göransson, G., Karlsson, J. and Lindgren, A. (1978) Influence of Roads on the Surrounding Nature. II. Fauna. Stockholm.

[24] Aaris-Sorensen, J. (1995) Road-Kills of Badgers (Meles meles) in Denmark. Annales Zoologici Fennici, 32, 31-36.

[25] Freeman, S. (2010) Western Weka Road-Kill at Cape Foulwind: Buller, New Zealand. New Zealand Journal of Zoology, 37, 131-146. http://dx.doi.org/10.1080/03014223.2010.482972

[26] Ramp, D., Caldwell, J., Edwards, K.A., Warton, D. and Croft, D.B. (2005) Modelling of Wildlife Fatality Hotspots along the Snowy Mountain Highway in New South Wales, Australia. Biological Conservation, 126, 474-490. http://dx.doi.org/10.1016/j.biocon.2005.07.001

[27] Ashley, E.P. and Robinson, J.T. (1996) Road Mortality of Amphibians, Reptiles and other Wildlife on the Long Point Causeway, Lake Erie, Ontario. The Canadian Field-Naturalist, 110, 403-412.

[28] Jaarsma, C., van Langevelde, F. and Botma, H. (2006) Flattened Fauna and Mitigation: Traffic Victims Related to Road, Traffic, Vehicle, and Species Characteristics. Transportation Research Part D: Transport and Environment, 11, 264-276. http://dx.doi.org/10.1016/j.trd.2006.05.001

[29] Seiler, A. (2005) Predicting Locations of Moose-Vehicle Collisions in Sweden. Journal of Applied Ecology, 42, 371382. http://dx.doi.org/10.1111/j.1365-2664.2005.01013.x

[30] Safaei, M. (2009) Study on Wildlife Mortality in Asian Road in Golestan National Park. MSc Thesis, Faculty of Environment and Energy, Islamic Azad University, Tehran, 198 p. (In Persian)

[31] Madjnoonian, H., Kiabi, B., Darrehshoori, F. and Meigouni, H. (1999) Golestan National Park: Biosphere Reserve. Department of the Environment of Iran, Tehran.

[32] Abdollahi, S. (2015) Modeling Habitat Requirements of Leopard (Panthera pardus) Using Genetic Algorithm in Golestan National Park. Environmental Resources Research, 3, 151-162. 
[33] Darvish Sefat, A. (2007) Atlas of Protected Areas of Iran. University of Tehran Publications, Tehran.

[34] Erfanian, B., Mirkarimi, S.H., Mahini, A.S. and Rezaei, H.R. (2013) A Presence-Only Habitat Suitability Model for Persian Leopard Panthera pardus Saxicolor in Golestan National Park, Iran. Wildlife Biology, 19, 170-178. http://dx.doi.org/10.2981/12-045

[35] Javanshir, K. (1976) Atlas of Woody Plants of Iran. National Society of Natural Resources and Human Environment Conservation, Tehran.

[36] Zebardast, L. (2011) Analyzing the Possibility of Utilizing Landscape Ecology to Reduce Uncertainty in Environmental Impact Assessment. Case Study: Road Crossing Golestan National Park. PhD Dissertation, Graduate Faculty of Environment, University of Tehran, Tehran, 235 p. (In Persian)

[37] Inbar, M., Shanas, U. and Izak, I. (2002) Characterization of Road Accidents in Israel Involving Large Mammals. Israel Journal of Zoology, 48, 197-206. http://dx.doi.org/10.1560/XGJB-VR67-RFEQ-N27A

[38] Dussault, C. and Prcjpo, M. (2006) Temporal and Spatial Distribution of Moose-Vehicle Accidents in the Laurentides Wildlife Reserve, Quebec, Canada. Wildlife Biology, 12, 415-425. http://dx.doi.org/10.2981/0909-6396(2006)12[415:TASDOM]2.0.CO;2

[39] Baker, P., Harris, S., Robertson, C., Saunders, G. and White, P. (2004) Is It Possible to Monitor Mammal Population Changes from Counts of Road Traffic Casualties? An Analysis Using Bristol's Red Foxes Vulpes vulpes as an Example. Mammal Review, 34, 115-130. http://dx.doi.org/10.1046/j.0305-1838.2003.00024.x

[40] Danks, Z.D. and Porter, W.F. (2010) Temporal, Spatial, and Landscape Habitat Characteristics of Moose-Vehicle Collisions in Western Maine. Journal of Wildlife Management, 74, 1229-1241.

[41] Colino-Rabanal, V.J., Boschl, J., Muñoz, M.J. and Peris, S.J. (2012) Influence of New Irrigated Croplands on Wild Boar (Sus scrofa) Road Kills in NW Spain. Animal Biodiversity and Conservation, 35, 247-252.

[42] Bailey, T.C. and Gatrell, A.C. (1995) Interactive Spatial Data Analysis. Longman Scientific \& Technical, Chelmsford.

[43] Okabe, A. and Yamada, I. (2001) The K-Function Method on a Network and Its Computational Implementation. Geographical Analysis, 33, 271-290. http://dx.doi.org/10.1111/j.1538-4632.2001.tb00448.x

[44] Okabe, A., Okunuki, K.-I. and Shiode, S. (2006) SANET: A Toolbox for Spatial Analysis on a Network. Geographical Analysis, 38, 57-66. http://dx.doi.org/10.1111/j.0016-7363.2005.00674.x

[45] Morelle, K., Lehaire, F. and Lejeune, P. (2013) Spatio-Temporal Patterns of Wildlife-Vehicle Collisions in a Region with a High Density Road Network. Nature Conservation, 5, 53-73. http://dx.doi.org/10.3897/natureconservation.5.4634

[46] Little, L.S., Edwards, D. and Porter, D.E. (1997) Kriging in Estuaries: As the Crow Flies, or as the Fish Swims? Journal of Experimental Marine Biology and Ecology, 213, 1-11. http://dx.doi.org/10.1016/S0022-0981(97)00006-3

[47] Rathbun, S.L. (1998) Spatial Modelling in Irregular Shaped Regions: Kriging Estuaries. Environmetrics, 9, $109-129$. http://dx.doi.org/10.1002/(SICI)1099-095X(199803/04)9:2<109::AID-ENV279>3.0.CO;2-L

[48] Yamada, I. and Thill, J. (2003) Empirical Comparisons of Planar and Network K-Functions in Traffic Accident Analysis. Proceedings of the 82nd Transportation Research Board Annual Meeting, Washington DC, January 2003 (cited in [49]).

[49] Spooner, P.G., Lunt, I.D. and Okabe, A. (2004) Spatial Analysis of Roadside Acacia Populations on a Road Network Using the Network K-Function. Landscape Ecology, 19, 491-499. http://dx.doi.org/10.1023/B:LAND.0000036114.32418.d4

[50] Mkanda, F.X. and Chansa, W. (2010) Changes in Temporal and Spatial Pattern of Road Kills Along the Lusaka-Mongu (M9) Highway, Kafue National Park, Zambia. South African Journal of Wildlife Research, 41, 68-78. http://dx.doi.org/10.3957/056.041.0114

[51] Grilo, C., Ascensão, F., Bissonette, J.A. and Santos-Reis, M. (2011) Do Well-Connected Landscapes Promote RoadRelated Mortality? European Journal of Wildlife Research, 57, 707-716. http://dx.doi.org/10.1007/s10344-010-0478-6

[52] Roger, E., Bino, G. and Ramp, D. (2012) Linking Habitat Suitability and Road Mortalities across Geographic Ranges. Landscape Ecology, 27, 1167-1181. http://dx.doi.org/10.1007/s10980-012-9769-5

[53] Underhill, J.E. and Angold, P.G. (1999) Effects of Roads on Wildlife in an Intensively Modified Landscape. Environmental Reviews, 8, 21-39. http://dx.doi.org/10.1139/a00-003

[54] Rosell, C., Navas, F., Pou, M. and Carol, J. (2010) Wild Boar Vehicle Collisions. Spatial and Temporal Patterns and Measures for the Mitigation of the Conflict on Wild Boar and Other Suids. 8th International Symposium, Sopron, 9193.

[55] Gaston, K. and Fuller, R. (2007) Biodiversity and Extinction: Losing the Common and the Widespread. Progress in Physical Geography, 31, 213-225. http://dx.doi.org/10.1177/0309133307076488 
[56] Gaston, K. and Fuller, R. (2008) Commonness, Population Depletion and Conservation Biology. Trends in Ecology \& Evolution, 23, 14-19. http://dx.doi.org/10.1016/j.tree.2007.11.001

[57] Gaston, K.J. (2008) Biodiversity and Extinction: The Importance of Being Common. Progress in Physical Geography, 32, 73-79. http://dx.doi.org/10.1177/0309133308089499

[58] Lennon, J., Koleff, P., Greenwood, J. and Gaston, K. (2004) Contribution of Rarity and Commonness to Patterns of Species Richness. Ecology Letters, 7, 81-87. http://dx.doi.org/10.1046/j.1461-0248.2004.00548.x 